\title{
Guidelines on Submitting Manuscripts
}

The Rural Educator is a peer-reviewed journal published three times per year. The primary mission of The Rural Educator is to provide educators in rural and small schools with researchbased articles on timely issues that inform education practice or have implications for rural education policy. The journal is particularly interested in receiving manuscripts related to the impact of federal and state reform policies on rural schools, funding and finance issues related to rural schools, and issues related to specific rural populations and community development. Three types of articles are accepted for publication: General Articles, Research Briefs, and Book Reviews: All manuscripts are submitted to blind peer review without reference to name or institution. Authors will be notified of acceptance or rejection as soon as the review process is completed. Issues of The Rural Educator are published in the fall, winter, and spring of each academic year. All manuscripts should be submitted as an e-mail attachment to theruraleducator@gmail.com.

\section{General Manuscript Guidelines}

- Submit in MS Word (.doc or .docx).

- Double-spaced.

- 12 point font.

- Use American Psychological Association (APA) 6th Edition for style, citation, and reference guidelines.

- Include tables and figures within the manuscript.

- Attach a cover sheet containing the following information about the author: name, institutional affiliation, address, zip code, telephone, e-mail address, and a brief biography. This bio should be a maximum of 50 words.

- Do not include the author's name within the manuscript.

- The author will be notified of editorial changes made to the manuscript; however, the Editor reserves the right to make such changes without author approval or notification if time does not permit.

\section{Article Guidelines}

- 5000-6500 words (including references).

- Include an abstract at the beginning of the manuscript not to exceed 150 words. The abstract should briefly describe the problem or topic, method, participants, findings, and conclusions.
- Include a listing of 3-5 keywords covering the topics addressed in the manuscript for use in keyword searches.

\section{Research Brief Guidelines}

The Rural Educator will consider and publish "Research Briefs" to promote the dissemination of novel and important research information in a format that does not require extensive journal space. Studies published as Research Briefs have a very focused and explicit purpose, and applied relevance to rural settings. Research Briefs should be no longer than 2000 words, inclusive of tables, figures, and references. Research Briefs should include the following:

- Introduction - provides a brief context for the current investigation, states its focus and purpose in a clear and cogent way, and identifies one or two main research questions;

- Methods - summarizes participants, instruments, independent or intervention variables, and procedures in a succinct but clear and replicable way;

- Results - presents key results in relation to the research purpose and main question (in tables and figures, whenever appropriate);

- Discussion - identifies key findings and notes important implications in relation to the existing knowledge base, field-based application, interpretive cautions (briefly noting and describing limitations), and possibly future directions; and

- References - includes a very limited number of seminal articles that are essential for readers to understand the nature, purpose, or methods of the research.

\section{Book Review Guidelines}

A book review should give readers an engaging, informative, and critical discussion of the work (length 750-1000 words). All references should be made in-text. 